\title{
LA PROBLEMÁTICA DE LA TRADUCCIÓN DE LA TERMINOLOGÍA JURÍDICA EN EL LIBRO MANUAL DE TRADUCCIÓNJURÍDICA ÁRABE-ESPAÑOL
}

\author{
Ziyad Mohammad Gogazeh \\ Universidad de Jordania
}

\begin{abstract}
Resumen: Este estudio traductológico aborda las dificultades y los obstáculos que he afrontado en la traducción de la terminología de los documentos jurídicos árabes en nuestro libro Manual de traducción jurídica Árabe-Español. En el presente trabajo se habla del sistema jurídico en España y Jordania, así como del lenguaje jurídico y la estructura de los documentos jurídicos en ambos países sobre todo aquellos usados en dicho Manual. Al final del artículo se exponen las dificultades que hemos encontrado durante la composición, así como las técnicas de adecuación jurídicas a las que recurrimos para resolver esas dificultades.
\end{abstract}

Palabras clave: Traducción jurídica, Árabe, Español, terminología, problemas.

Abstract: The current study approaches the difficulties and the problems encountered in the translation of the terminology of the Arabic legal documents in our book Manual de traducción jurídica published in Spain. The present article talks about the legal system in Jordan and Spain, as well as the legal language and the structure of the legal documents in both countries, including all those used in the Manual. The final part exposes the difficulties encountered in the book, in addition to the techniques of adequacy which we employed to resolve these difficulties.

Keywords: Legal translation, Arabic, Spanish, terminology, problems.

\section{El corpus del estudio}

El corpus de este estudio lo constituye el libro titulado Manual de traducción jurídica Árabe-Español, publicado en la editorial española ArCibel Editores en el año 2007. El manual está dividido en doce capítulos temáticos bien diferenciados entre ellos que recogen documentos expedidos por las administraciones públicas. Los capítulos están divididos temáticamente en Solicitudes, Certificados, Recibos, Formularios notariales, Letras de cambio, Declaraciones, Documentos 
del tribunal islámico, Documentos de los tribunales civiles, Certificados eclesiásticos, Certificados de estado civil, Contratos y Certificados académicos.

Todos los documentos incluidos en los capítulos del libro son formularios de ámbitos de derecho islámico redactados en lengua árabe. Con pocas excepciones, la mayoría de ellos se han recopilado a partir de la documentación emitida por las instituciones administrativas jordanas. Dichos documentos árabes son los expedidos por las autoridades de la administración saudí, egipcia y marroquí con el objetivo de ofrecer otras variantes y distintos ejemplos en el carácter y naturaleza de los documentos sometidos a la traducción.

La metodología seguida en la estructuración del libro ha consistido en situar el documento jurídico original árabe junto a su traducción castellana de forma que el Manual pudiera servir como una guía imprescindible para todos esos que trabajen en el campo jurídico y en el de la traducción jurídica.

Para que el Manual citado pueda considerarse como un libro eminentemente didáctico dirigido a los alumnos de traducción, se le añadió un anexo de dos índices, de los cuales el primero recoge catorce textos jurídicos árabes sin traducción castellana de forma que sirvan como ejercicios prácticos en el aula. Esos textos van acompañados de palabras clave en la lengua de salida, situadas en los márgenes con sus equivalentes en la lengua de llegada. Teniendo en consideración el objetivo didáctico del Manual para aquellos alumnos que estudian la traducción del árabe al español y viceversa, el segundo índice del Manual recoge textos castellanos empleados por las autoridades administrativas españolas a fin de que el Manual incluya al final dos índices de ejercicios que recojan textos árabes y españoles dirigidos tanto a los alumnos como a los profesores de traducción del árabe al español y viceversa.

La obra en su totalidad incluye aproximadamente catorce mil términos jurídicos y debemos mencionar específicamente que las traducciones castellanas de los documentos jurídicos han sido acreditadas como versiones oficialmente aceptadas y aceptables de los documentos árabes por variadas misiones diplomáticas de habla hispana. ${ }^{1}$

\section{El sistema jurí dico en Jordania y España}

Antes de plantear la problemática de la traducción de la terminología jurídica en nuestro Manual, es conveniente situar el contexto al que se refiere y, por ello, es preciso referirnos brevemente a los sistemas jurídicos de España y Jordania.

Es bien sabido que Jordania y España pertenecen a dos contextos jurídicos diferentes teniendo en cuenta que el sistema jurídico de una nación es, en gran medida, una manifestación de sus ideologías, de sus modos de vivir, de sus procesos históricos y culturales y representa, en definitiva, una parte del conjunto total del bagaje nacional de cada país.

1 Gogazeh, Z., Manual de traducción jurídica Árabe-Español, Sevilla, ArCibel. 
El componente ideológico y cultural que llevó incidió con mayor fuerza en las diferencias existentes entre el sistema jordano y español es sin duda ninguna la religión musulmana teniendo en cuenta además que el sistema jordano, al igual que el de los demás sistemas jurídicos árabes se atiene en gran parte de su consolidación a los sistemas jurídicos occidentales, sobre todo el anglosajón, sin perder de vista elementos de los demás códigos jurídicos occidentales.

La existencia del Islam como una religión predominante en las sociedades árabes y específicamente en nuestro caso jordano, dejó sus considerables huellas en la formación de los ordenamientos en el sistema jurídico jordano y sobre todo en todo lo que tiene que ver con el código civil. Las autoridades políticoreligiosas árabe, desde sus comienzos establecieron el mensaje muy claro de que el Islam era un sistema de vida y por ello, tenía que aplicarse a las sociedades en su conjunto. Es decir, desde este punto de vista, el Islam no se tomó practicando parte y descuidando otra sino que tiene que vivirse y tomare íntegramente.

Cuando aconteció la crisis económica en Estados Unidos en 2008, una de las soluciones propuestas por los expertos económicos estadounidenses fue seguir el sistema financiero islámico. Sin embargo, una vez analizada la cuestión, los mismos teóricos y expertos rectificaron su propuesta pues advirtieron que dicha sugerencia no tendría éxito porque no se podría aplicar solamente una parte del sistema. Para que la experiencia tuviera éxito se tendría que tomar el sistema islámico íntegramente con todas sus manifestaciones y prácticas y en todos los niveles de la vida.

Ésta es prácticamente la visión filosófica e ideológica de la práctica del Islam aunque hoy en día se sabe que los sistemas jurídicos árabes no siguen las leyes islámicas al pie de la letra sino que han admitido algunos elementos de varios sistemas jurídicos. Probablemente, el más destacado es el sistema anglosajón que junto con el francés tuvo la mayor repercusión e influencia en el sistema jurídico árabe. El sistema jordano, en realidad, no hace excepción a la regla siendo ése una combinación entre el sistema napoleónico-francés, de las leyes islámicas y el de las leyes tribales.

Desde su revelación el Corán es considerado por los musulmanes como un libro sagrado revelado por Dios, que vino para regular y ordenar la vida del musulmán en particular y la sociedad musulmana en general, de modo que habla de la regulación de muchas materias sociales como el código penal, el derecho mercantil y el derecho familiar.

Es bien sabido que hoy día no existe ningún estado islámico practicante extricto sino que casi todos los países musulmanes viven un estado laico si excluimos los ejemplos saudí y afaganí. Ese laicismo significa una mezcla de las leyes occidentales, islámicas y tribales y lo que nos interesa en este estudio es la repercusión del sistema jurídico occidental en el árabe y específicamente en el caso jordano. Antes de hablar de la influencia del sistema occidental en el jordano convendría dar a conocer cómo este sistema se ha estructurado y 
construido. La cita siguiente está recogida de la página web oficial del fallecido rey jordano Hussein en la que se habla del sistema jurídico jordano:

"El artículo 99 de la Constitución divide los tribunales en tres categorías: los tribunales civiles, religiosos y especiales. Los tribunales civiles ejercen su jurisdicción en materia civil y penal de conformidad con la ley, y tienen jurisdicción sobre todas las personas en todos los asuntos civiles y penales, incluyendo los casos presentados en contra del gobierno. Los Tribunales civiles son Tribunales de primera instancia, tribunales de apelación, Altas Jurisdicciones Administrativas y el Tribunal de Casación (Tribunal Supremo). El sistema legal civil jordano tiene su fundamento en el Código Napoleónico, un código legal francés implementado en Egipto en el siglo XIX.

Los tribunales religiosos incluyen la ley sagrada islámica y los tribunales de otras comunidades religiosas, a saber, los de la minoría cristiana. Los tribunales religiosos tienen tribunales de primera instancia y de apelación y se ocupan sólo de asuntos de derecho personal, como matrimonio, divorcio, herencia y custodia de los hijos. Los tribunales religiosas que entienden de la ley sagrada islámica también tienen jurisdicción sobre los asuntos relacionados con los bienes de las instituciones islámicas)". ${ }^{2}$

En el sistema jurídico jordano la parte que ha sido menos influida por el sistema jurídico occidental es el Código Civil, es decir, la parte que se interesa por las materias sociales tales como el divorcio, la herencia, el matrimonio, la custodia de los niños, etc.

Las dos fuentes capitales de la legislación islámica son El Corán y la Tradición Profética o Sunna. A esas dos fuentes fundamentales se añaden tres fuentes más que son la Analogía, el Consenso y el esfuerzo de razonamiento a las que se suele acudir en los casos polémicos cuya solución no figura claramente indicada en las dos fuentes capitales y que están sujetos a distintas interpretaciones.

Las leyes dogmáticas que vienen en las fuentes del Islam han permanecido intactas en el código civil jordano contemporáneo sin modificación, alteración o desviación ninguna, de modo que todo lo relacionado con las materias sociales se practica, tal como ordenan las fuentes islámicas. Dichas materias no sufrieron influencia occidental porque su práctica tal como decreta el Islam forma parte de la creencia y la aceptación del musulmán de lo revelado por el Creador. Si se practican fuera del marco dogmático ordenado serían nulas, como el caso del matrimonio, por ejemplo. De otra parte, las leyes religiosas islámicas tienen mucha presencia en el sistema jurídico jordano y sobre todo el Código Civil por ser el Islam, según la Constitución, la religión oficial del Estado y éste es el caso de todos los países árabes, pero como se sabe la práctica de ello es relativa.

2 Royal Cort, Office of King Hussein, http://www.kinghussein.gov.jo/government4.html, 23-01-2012. 


\section{La estructura y el lenguaje del documento jurídico jordano y español}

Los sistemas jurídicos de Europa y el mundo árabe comparten líneas generales $y$, por tanto, tienen muchas cosas en común en lo que se refiere a la terminología y a los distintos tipos de documentos empleados en el ámbito jurídico, ya que como se dijo anteriormente el sistema español es similar al sistema francés y éste es similar al anglosajón, y el jordano está basado en el francés. Ello quiere decir que los sistemas sujetos a nuestro estudio están dentro del mismo marco jurídico general, conservando cada uno de aquellos sistemas sus respectivas peculiaridades.

En la mayoría de los casos, la estructura de los documentos jurídicos jordanos se asemeja a la estructura general del texto jurídico español o el occidental en general, en lo que se refiere al modo de introducir el documento, su división en párrafos y epígrafes y la forma de finalización. Tampoco ello se aleja de la estructura propia de la división de un documento jurídico perteneciente al sistema jurídico canadiense, norteamericano o australiano. Ello quiere decir que puede haber un documento jurídico universal y una terminología jurídica universal que compartan líneas y marcos generales comunes pese a las diferencias de los sistemas jurídicos y los idiomas a través de los que se expresan.

Para mostrar lo anterior tomamos dos ejemplos jurídicos de dos formularios de apelación jordano y español. El siguiente es una traducción de un formulario de Apelación en contra de un veredicto utilizado por el Ministerio de Justicia jordano y tomado de mi libro sujeto a este estudio:

\section{Ministerio de Justicia \\ Apelación en contra de Veredicto}

Para el Tribunal de Apelación por delitos en...

El apelante..., nombre del padre..., residente en...

El apelado:

El Fiscal.

Tema de apelación:

A / $/ 20 \ldots$ Veredicto ${ }^{\circ} \ldots$ fue expedido sobre mí en el Caso no $\ldots$ en el año $20 \ldots$ ante del Tribunal de...

La Apelación implica:

1.

2.

3.

Mientras yo soy inocente del crimen del cual yo he sido declarado culpable por razones que durante los procesos judiciales serán establecidas a la vista, y mientras el veredicto contravenga las normas y la ley, y mientras la sanción 
sea desmedida al crimen del cual yo he sido declarado culpable, yo, dentro del periodo legal, por la presente SOLICITO QUE:

1. Mi Apelación sea formalmente aceptada para que pueda ser presentada dentro del periodo legal y cumplir las condiciones estipuladas.

2. Mi Apelación sea sustantivamente aceptada, la decisión en contra de la Apelación sea rescindida y mi inocencia o no responsabilidad sea establecida.

3. Si el Tribunal me impone una sanción, las mayores misericordias serán ejercidas por definir la naturaleza de la sanción.

4. El apelado debería pagar los honorarios y costas.

Apelante: $\quad$ / $/ 20 \ldots{ }^{3}$

El segundo texto, que exponemos a continuación, es un formulario de un recurso de Apelación sacado de la página web http://www.todalaley.com y utilizado en los Tribunales españoles:

Recurso de apelación

Al juzgado de instrucción $n^{\circ}(.$.$) de (...)$

Don (...), Procurador de los Tribunales y de Don (...), según queda acreditado en autos de Procedimiento Ordinario número (...), como mejor proceda en derecho, DIGO:

Que con fecha de (...) nos ha sido notificado el auto dictado por el Juzgado al que me dirijo en fecha de (...) de (...) de (...) por la que se desestima el Recurso de Reforma interpuesto por esta parte contra (...) dictado por dicho Juzgado.

Que por el presente escrito, dentro del plazo legal conferido, interpongo en tiempo y forma RECURSO DE APELACIÓN ante la audiencia Provincial, contra (...) en base a los siguientes fundamentos; (...)

En su virtud,

SUPLICO AL JUZGADO.

Que tenga por presentado este escrito y las copias que se acompañan, lo admita (señalar, según el caso, si en un solo efecto o en ambos efectos), teniendo por interpuesto Recurso de Apelación en tiempo y forma contra (...) dictado en autos de Procedimiento Ordinario núm.(...) por el Juzgado al que me dirijo, elevándose a la Audiencia Provincial de (...), para que en su día se dicte resolución acordándose (...).

Por ser justicia que ruego,

$\operatorname{En}(\ldots)$ a $(\ldots)$ de $(\ldots)$ de $(\ldots) .^{4}$

3 Gogazeh, Z., Obra Citada. 121.

${ }^{4}$ Acción Internacional de Ayuda académica S.L.L, http://www.todalaley.com/mostrarFormulario163.htm, 13-11-2011. 
Se aprecia muy claramente que ambos formularios tienen casi la misma estructura pese a que los dos son usados para dos diferentes peticiones. La manera en la que los dos formularios van encabezados es casi la misma, la forma de introducir los dos formularios, sus divisiones estructurales, y la forma de cerrar ambos formularios, a pesar de que no sean idénticas, guardan evidentes parecidos. La estructura, la división, y las maneras de introducir o finalizar un equivalente formulario en inglés o francés tampoco sería distinta.

Por lo que atañe al lenguaje de los documentos en el sistema jurídico jordano y español, como se aprecia en los dos formularios expuestos arriba, el lenguaje jurídico es un lenguaje que se aleja de las emociones y del estilo literario y se acerca mucho al lenguaje de los textos científicos, por lo cual en el proceso traductológico se tiene que respetar el orden y la división que aparecen y efectuar una traducción casi literal del material textual con mucho cuidado en la elección de los equivalentes jurídicos de los términos que figuran en el material textual de la lengua de salida.

\section{La traducción de la terminología jurídica árabe: dificultades y técnicas de manejo.}

El hecho de que el Islam, como hemos dicho, sea un modo de vida cuyas leyes están conservadas principalmente en las dos fuentes capitales de la legislación islámica, que son el Corán y la Tradición profética, influyó considerablemente en el sistema jurídico jordano y sobre todo en la parte que concierne la materia social, es decir en el código civil árabe en general y el jordano en particular. Esta pertenencia a un sistema jurídico tan influido por un dogma que ejerce un papel importante en todos los sectores de la vida, hizo surgir nueva terminología y nuevo material jurídico inexistente en el sistema jurídico occidental en general y en el español en particular.

Durante nuestro trabajo práctico en la elaboración del Manual, el capítulo que más trabajo costó es el capítulo de los documentos del Tribunal islámico, ya que no es nada fácil verter los documentos que hemos elegido como ejemplares de los formularios del Tribunal islámico jordano. El primer problema que se nos presentó fue la inexistencia de la equivalencia jurídica en el sistema jurídico español o, más bien, la falta de un formulario equivalente en castellano por lo cual tuvimos que recurrir a estrategias de adecuación semántica para producir una versión castellana comprensible para los lectores españoles. Por ejemplo en el mencionado capítulo se tomaron cuatro formularios del divorcio, y es bien sabido que en Jordania tenemos únicamente un matrimonio que es el matrimonio religioso musulmán celebrado según las leyes islámicas. Esta materia social -quiero decir el divorcio- no sufrió ninguna influencia o modificación de leyes ajenas y se quedó tal como se ordenó en las fuentes de legislación islámica. 
En el Islam existen tres modalidades de divorcio $^{5}$ y para cada una de estas clases se elaboraron formularios y materiales jurídicos respetando el marco general de un documento jurídico occidental pero produciendo un documento o formulario inexistente en la cultura jurídica del otro. Puesto que la meta principal de la traducción es producir un texto coherente, aceptable y comprensible para el lector español, en nuestro caso tuvimos que recurrir, en nuestra traducción de esos formularios, a dos técnicas de manejo textual y terminológico:

La primera es la técnica de la traducción explicativa. Hemos recurrido a esta técnica por nuestro conocimiento de que el público al que nuestra traducción va dirigida no tiene un conocimiento sólido de la cultura jurídica de la materia social en los países musulmanes. Por ello éramos muy conscientes de que si hubiéramos traducido los documentos mediante la técnica de la traducción léxica o sea palabra por palabra, se habría producido una traducción comprensible léxicamente pero incomprensible jurídicamente para el público español. Lo dicho queda aclarado en la tabla siguiente:

\begin{tabular}{|c|c|c|}
\hline Título del formulario en árabe & Traducción literal & $\begin{array}{c}\text { Traducción explicativa seguida } \\
\text { en el Manual }\end{array}$ \\
\hline حجة رجعة & Certificado de vuelta & $\begin{array}{l}\text { Certificado para volver a } \\
\text { casarse para una esposa } \\
\text { divorciada }\end{array}$ \\
\hline طلاق معلق & Divorcio pendiente & $\begin{array}{l}\text { Certificado de divorcio } \\
\text { condicional }\end{array}$ \\
\hline طلاق بائن قبل الدخول & $\begin{array}{l}\text { Divorcio definitivo antes } \\
\text { de la entrada }\end{array}$ & $\begin{array}{l}\text { Certificado de divorcio } \\
\text { irrevocable antes de la } \\
\text { consumación del matrimonio }\end{array}$ \\
\hline طلاق بائن مقابل الابراء بعد الدخول & $\begin{array}{l}\text { Divorcio definitivo a } \\
\text { cambio de librar después } \\
\text { de la entrada }\end{array}$ & $\begin{array}{l}\text { Autorización de divorcio } \\
\text { irrevocable sin responsabilidad } \\
\text { después de la consumación del } \\
\text { matrimonio }\end{array}$ \\
\hline
\end{tabular}

Como se ve en la tabla, consideramos más acertado recurrir a esta técnica de traducción explicativa con el fin de ofrecer una versión accesible hasta cierto punto al lector español.

${ }^{5}$ En su artículo "E1 divorcio en el Islam" en Webislam, Ndeye Andújar dice: "Según el fiqh clásico hay diferentes categorías de divorcio: revocable, irrevocable menor y irrevocable mayor. El revocable: el marido puede volver a estar con su mujer antes de que se haya acabado su período de espera de cuatro meses y no hace falta que se vuelva a casar ni que le dé otra dote. El irrevocable menor, cuando se ha acabado el período de espera, se puede volver a casar una segunda y tercera vez, pero con el consentimiento de la mujer, con un nuevo contrato y una nueva dote. Y el irrevocable mayor, por tercera vez, se ha de esperar a que la mujer se vuelva a casar y que su nuevo marido se muera o se divorcie de ella antes de poderse casar con él. El nuevo marido, el que la hace lícita y el ex-marido no se pueden poner de acuerdo, tal y como dicen algunos ahadiz, se maldice esta complicidad". N. Andujar, "El divorcio en el Islam", http://www.webislam.com/ articulos/30422-el_divorcio_en_la_ley_islamica.html, Webislam, 21-09-2011. 
La segunda técnica que hemos aplicado en el Manual, es la técnica de ofrecer la equivalencia jurídica normalizada. Dicha técnica surgió en el caso de que el término jurídico árabe tuviera un uso semejante en el sistema jurídico español, como en los documentos de arrendamiento, depósito, fianza, compraventa, denuncia... etc. En semejante material jurídico se dio el equivalente jurídico español puesto que tiene la misma connotación en la lengua de llegada.

\section{BIBLIOGRAFÍA}

AndújA, N., "El divorcio en el Islam”, http://www.webislam.com/articulos/30422-el_ divorcio_en_la_ley_islamica.html, Webislam, 21-09-2011.

Boceuet, C., Pour une méthode de la traduction juridique, Lausanne, CB Service. 1994.

Beylard-Ozeroff, A., Králová Jana, B., Translators' Strategies and Creativity, Amsterdam, John Benjamins.1998.

Connu, G., Linguistique juridique, Paris, Éditions Montchrestien, 1990.

Cortés, J., Diccionario de árabe culto moderno, Madrid, Gredos, 1996.

Jiménez Hurtado, C., La estructura del significado en el texto. Análisis semántico para la traducción, Granada, Editorial Comares, 2000.

FERIA,M.,La traducción fehaciente del árabe:fundamentos históricos, jurídicos y metodológicos. Tesis doctoral. Málaga, Universidad de Málaga, 2001.

Feria, M., Traducir para la justicia, Granada, Comares, 1999.

Jiménez Serrano, O., La traducción técnica inglés-español: didáctica y mundo profesional, Granada, Comares, 2002.

García Y., En torno a la traducción: teoría, crítica e historia, Madrid. Gredos, 1989.

Gogazeh, Z. y Pacheco, J.A, La traducción como medio de comunicación intercultural, el ejemplo de los refranes, Amman, Alamiriya, 2008.

Gogazen, Z. Al-Afif, A., Manual de traducción jurídica Árabe-Español, Sevilla, ArCibel, 2009.

Maillot, J., La traduction scientifique et technique, Paris, Eyrolles, 1981.

Maley, Y., "The Language of the Law", Language and the Law, London, Longman, 1994.

Mayoral Asensio, R., Translating official documents. Manchester. St.Jerome Publishing, 2003.

Newmark, P., Manual de traducción, Madrid, Cátedra, 1999.

Mounin, G., Les problèmes théoriques de la traduction, Paris, Gallimard, 1986.

Monzó, E. y BorjA, A., La traducción y la interpretación en las relaciones jurídicas internacionales, Castelló, Universitat Jaume I, 2005.

Levi,J. and Graffam Walkker, A., Language in the Judicial Process, New York, Plenum Press, 1990. 
Royal Cort, Office of King Hussein I, http://www.kinghussein.gov.jo/government4. html, 23-01-2012

Cano Ávila,P., "Compraventa de un turno de riego", Revista de filología de la Universidad de La Laguna, vol. 17 (1999) p. 221-232.

Peña, S. y Guerro, M., Traductologia, Málaga, Universidad de Málaga, 1981.

San Ginés Aguilar, P. y Ortega Arjonilla, E., Introducción a la traducción jurídica y jurada (francés-español), Granada, Comares, 1997.

Toury, G., Descriptive Translation Studies, John Benjamins, Amsderdam, 1995.

Acción Internacional de Ayuda académica S.L.L, http://www.todalaley.com/ mostrarFormulario163.htm, 13-11-2011.

Nombre del autor: Ziyad Mohammad Gogazeh

Dirección-e: jordania71@hotmail.com

Dirección postal: $\quad$ P.O Box 13837 Amman 11942, Jordan

Fecha de recepción: 15/02/2012

Fechade aceptación: 04/03/2013 